\title{
The National Jordanian Experts Consensus on Diagnosis and Treatment of Prediabetes
}

\author{
Mohamad Omar Abu Hijleh", *, Firas Annabi ${ }^{2}$, Mousa Abujbara ${ }^{3}$, Abdelkarim Alkhawaldeh ${ }^{4}$, \\ Fares Haddad $^{5}$, Jihad Haddad ${ }^{6}$, Muwafaq Alhyari ${ }^{6}$, Harry Howlett $^{7}$, Nadim Jarrah ${ }^{8}$, \\ Nadima Shegem ${ }^{9}$, Murad Al-Naqshbandi ${ }^{10}$ \\ ${ }^{1}$ Jordan Center for Thyroid, Endocrine Diseases and Diabetes, Jordan Hospital \& Medical Center, Amman, Jordan \\ ${ }^{2}$ Islamic Hospital, Amman, Jordan \\ ${ }^{3}$ The National Center for Diabetes, Endocrinology and Genetics, Amman, Jordan \\ ${ }^{4}$ Al Raja'a Medical Center, Amman, Jordan \\ ${ }^{5}$ King Hussein Medical Center, Royal Medical Services, Amman, Jordan \\ ${ }^{6}$ Prince Hamzah Hospital, Ministry of Health, Amman, Jordan \\ ${ }^{7}$ Global Diabetes Amersham, London, United Kingdom \\ ${ }^{8}$ The Specialty Hospital, Amman, Jordan \\ ${ }^{9}$ Caritas Jordan, Amman, Jordan \\ ${ }^{10}$ Merck Serono Middle East, Dubai, UAE
}

Email address:

abuhijlehdromar@gmail.com (M. O. A. Hijleh)

${ }^{*}$ Corresponding author

\section{To cite this article:}

Mohamad Omar Abu Hijleh, Firas Annabi, Mousa Abujbara, Abdelkarim Alkhawaldeh, Fares Haddad, Jihad Haddad, Muwafaq Alhyari, Harry Howlett, Nadim Jarrah, Nadima Shegem, Murad Al-Naqshbandi. The National Jordanian Experts Consensus on Diagnosis and Treatment of Prediabetes. International Journal of Diabetes and Endocrinology. Vol. 6, No. 1, 2021, pp. 46-53. doi: $10.11648 /$ j.ijde.20210601.18

Received: February 6, 2021; Accepted: February 23, 2021; Published: March 4, 2021

\begin{abstract}
Background and aims: The prevalence of prediabetes is increasing in Jordan and the Middle East region, which is leading to increased risk of type 2 diabetes and micro- and macro-complications. The aims of the expert panel were to understand and evaluate the current prediabetes situation and practice in Jordan and make recommendations to standardize the management of patients with prediabetes in Jordan. Methods: A panel of diabetes experts met to discuss and review all the current literature related to the region and international guidelines on prediabetes. The panel evaluated and developed a comprehensive understanding, addressing the definition, screening, diagnosis, pharmacological treatment, and management of prediabetes with consideration of local factors. Results: The experts relied on international data to establish criteria with cut-off values for screening and diagnosis to identify asymptomatic patients with prediabetes and diabetes. The panel made protocol recommendations, including lifestyle modifications, and developed potential treatment algorithms to provide guidance on the overall management for Jordanian prediabetic patients. Conclusion: The panel of experts reached consensus recommendations with a tailored detection, screening, and treatment algorithm in anticipation for a country wide adoption and implementation. These recommendations would help increase awareness of prediabetes in Jordan and create local guidelines to better serve Jordanian physicians in the management of patients with prediabetes.
\end{abstract}

Keywords: Prediabetes, Consensus, Jordan, Management

\section{Introduction}

The number of adults with IGT (2019 estimates) is 374 million with almost half of them below 50 years old; this is due to the high prevalence of obesity in this age group [1, 2]. This number is also expected to increase to 548 million 
adults between 20 and 79 years old by 2045, which represents $8.6 \%$ of the adult population [1]. These increasing numbers are associated with an increase in diabetes related morbidity and mortality worldwide [1]. IFG or IGT or raised glycated hemoglobin $>5.5 \%$ (AACE), $>5.7 \%$ (ADA) to $<6.5 \%$ levels represent "Prediabetes" which is a stage of intermediate hyperglycemia. It usually occurs when a person's blood glucose level is higher than normal, but not high enough to be diagnosed with diabetes as defined by the 2018 Canadian Practice Guidelines [3], by the WHO [4] and the ADA [5].

Prediabetes increases the short-term risk of type 2 diabetes mellitus (T2DM) with a yearly conversion rate of 5 to $10 \%[6,7]$. Prediabetes is associated with an increased risk of retinopathy [8], nephropathy [9], heart failure [10], and coronary heart diseases [11]. Observational studies have shown that diabetes complications are linked to prediabetes [12]. Therefore, understanding prediabetes and managing it properly and timely, helps to decrease blood glucose levels and delay the progression to diabetes [13-15] thus reduces the global epidemic of T2DM [13]. It also reduces diabetes related cardiovascular and microvascular disease $[16,17]$.

The prevalence of prediabetes in MENA region is alarming [18]; 15.2\% in Saudi Arabia [19], 14.4\% in Kuwait [20], 14.7\% in Bahrain [21], 7.0\% in UAE [22], 29.1\% in Iraq [23], 35.1\% in Oman [24], 13.8\% in Qatar [25], 9\% in Yemen [26], 5.9\% in Palestine [27], 8.6\% in Syria [28], 5.1\% in Lebanon [29], 5.9\% in Tunisia [30], 8.6\% in Libya [31] and $5.5 \%$ in Morocco [32]. In Jordan, according to the National Center for Diabetes, Endocrinology and Genetics JUST Study in 1995, the prevalence of IGT was 9.8\% [33], $9.3 \%$ according to the Ministry of Health study in 1996 and $39.8 \%$ in 2007 [34], 13.4\% in the 2004 National study and $25.4 \%$ in 1996 [34]. Thus, prediabetes is increasing at an alarming rate in Jordan.

Despite the high prevalence of prediabetes worldwide, in MENA region and in Jordan in addition to the risk of diabetes related complications, there are few recommendations regarding prediabetes diagnosis and treatment, and there are no approved licensed medications for the treatment of IFG and IGT in the Middle East. In addition, third party payers do not cover the costs of lifestyle changes for prediabetes and physicians have different opinions and approaches regarding its diagnosis and management. Moreover, there is an absence of defined targets for risk factors including glucose levels, weight, BP, and lipid levels [6].

\section{Objectives}

The main objective of the expert panel is to form a comprehensive understanding on the perspective of prediabetes definition, prevalence, diagnosis, management and the potential use of pharmacological agents in the management in Jordan.

\section{Methodology}

A panel of 10 diabetes experts (9 Jordanian and one international) met on the 24th of September 2018 to understand $\&$ evaluate the status of prediabetes diagnosis and treatment in Jordan and recommend its proper management protocol while taking into consideration the local factors. The experts conducted a comprehensive literature review search of databases such as Medline, EMBASE and Cochrane. The panel also reviewed websites of IDF, WHO, and the Ministry of Health of Jordan. Certain key terms were utilized to identify the relevant literature such as "prediabetes", "diabetes", "Middle East", "Jordan", "definition", "screening", “diagnosis", "treatment", "practice guidelines" and "complications".

\section{Results}

\subsection{Definitions}

"Prediabetes", "Non-Diabetic Hyperglycemia", "Diabetes stage 1" or "Early Stage of Diabetes"?

"Prediabetes" is defined as the transitional state that precedes the clinical onset of diabetes [35]. The IDF prefers the term "non-diabetic hyperglycemia" marked by an increase of blood glucose to a certain level below the diabetes range [4].

The ADA classifies prediabetes as an established risk factor for diabetes mellitus according to glycemic state of IGT and/or IFG and/or HbA1c [5].

In some cases the changes in glucose tolerance may be bidirectional, such as patients with T2DM who may revert to IGT status with weight loss [13], therefore "diabetes stage 1" or "early stage of diabetes" cannot be adopted. Thus, the expert panel agreed on the "Prediabetes" terminology.

What is the Prevalence of Prediabetes in Jordan?

According to the $8^{\text {th }}$ edition of the IDF Diabetes Atlas, the national diabetes estimated prevalence in Jordan is $9.5 \%$ among people aged between 20 and 79 years old and the diabetes age adjusted comparative prevalence is $11.8 \%$. These levels set Jordan as one the countries with a medium to high prevalence of diabetes [36]. The panel stated that this prevalence is outdated because it considers a population of 6 million while the population in Jordan is currently 10 million.

In the Middle East, there is a high prevalence of diabetes and it is expected to reach $72 \%$ by 2045 [37]. A study undertaken in Jordan, compared the mortality level in patients with diabetes and the number of deaths related to high blood glucose, showed that the prevalence of diabetes and related risk factors is $13.1 \%$, obesity $28.1 \%$, overweight $62.3 \%$ and physical inactivity $12.1 \%$ [38].

The DECODE study that evaluated prediabetes prevalence by age and sex showed an increase in the prediabetes prevalence in advanced age [39]. Furthermore, a crosssectional study [40] showed that in 1821 students aged 18-25 years, the prediabetes prevalence was $18 \%$.

A third study conducted in genetically isolated populations in Jordan showed that the prevalence of IFG was $18.5 \%$ for Circassians and $14.6 \%$ for Chechens, the prevalence of 
diabetes was $9.6 \%$ for Circassians and $10.1 \%$ for Chechens [41]. The study also demonstrated that the prevalence of IFG and diabetes was significantly higher in men, older age groups, married, subjects of lower educational level, past smokers, and obese subjects. The low HDL-cholesterol was the most common abnormality in the two populations.

Therefore, the risk pattern for prediabetes in Jordan (risk factors, complications, risk of becoming prediabetic) is nearly similar to the one seen in other countries with little differences in prevalence.

\subsection{Screening for Prediabetes}

Development of prediabetes involves several factors such as genetics, insulin resistance, defects in insulin secretion, glucotoxicity, lipotoxicity, impaired incretin release, amylin accumulation, inflammation, oxidative stress and decrease beta-cell mass leading to beta-cell dysfunction [42]. Several groups have developed recommendations for prediabetes screening including the Canadian Practice Guidelines, the USPSTF and the ADA [3, 43, 44].

As per the Canadian Guidelines, prediabetes can occur silently; thus, it is crucial to repeat diagnostic testing if the person is known to have risk factors such as high BP, high levels of LDL-cholesterol, low levels of HDL-cholesterol and increased body weight and visceral fat [3].

According to the ADA, prediabetes is associated with obesity (abdominal or visceral obesity), dyslipidemia, high triglycerides and/or low HDL-Cholesterol, and HTN. Therefore, the ADA considers several criteria for both testing for diabetes and prediabetes (Table 1) [5].

Table 1. Criteria for Testing for Diabetes or Prediabetes in Asymptomatic Adults ${ }^{6}$.

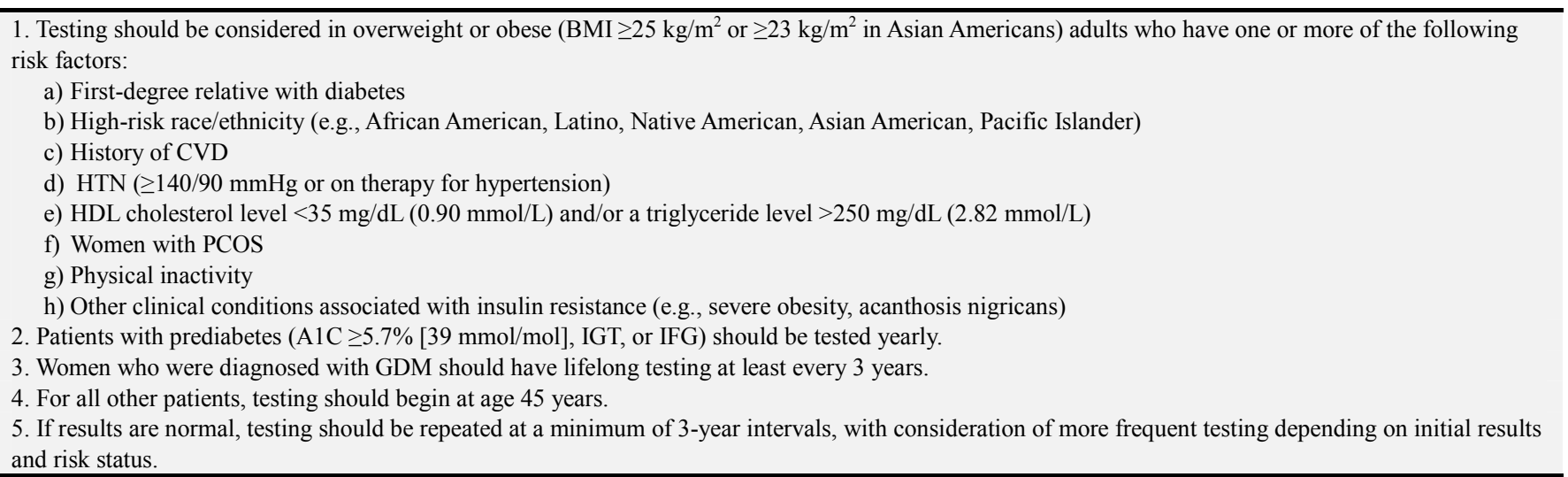

The USPSTF recommends screening for abnormal blood glucose as part of cardiovascular risk assessment in adults aged 40 to 70 years who are overweight or obese [43].

The IDF has also developed an online screening questionnaire evaluating the risk of having T2DM including 8 questions regarding the person's medical and family history. This test is based on the Finnish Diabetes Risk Score (FINDRISC) [45].

Due to high prevalence of obesity \& other risk factors; The Jordanian experts panel recommendation for screening is summarized in table 2.

Table 2. Jordanian Recommendation for Prediabetes Screening.

\begin{tabular}{ll}
\hline No risk factors (repeat in 3 years) & $>40$ years old \\
$\geq 1$ risk factor & 25 years old \\
$\mathrm{BMI} \geq 25 \mathrm{~kg} / \mathrm{m}^{2}$ & All age categories \\
\hline
\end{tabular}

The experts also recommend the Arabic validated/translated IDF questionnaire to be adopted.

\subsection{Prediabetes Diagnostic Tests and FBG and HbAlc Cut off Values}

Prediabetes is not yet regarded as an independent disease or disease stage but rather as a major risk factor for diabetes, micro and macrovascular complications. It is very important to realize that individuals with prediabetes when compared with normoglycemic subjects already have a "diabetic phenotype".
Thus, on top of hyperglycemia, these subjects usually have a higher BMI, waist circumference. Moreover, they are frequently dyslipidemic and have an elevated BP indicating that they have different components of the metabolic syndrome [46].

The diagnostic criteria for prediabetes have changed several times over the decades. The previous concept of nondiabetic hyperglycemia defined by the NDDG in 1979 was glucose intolerance mainly based on the OGTT; this was reviewed in 1997 by an international expert committee and endorsed by WHO in 1998 [46].

Various organizations, such as the WHO or the ADA have defined prediabetes with variable criteria. There are in fact, several types of blood tests and additional biomarkers that can be considered to determine if a person has prediabetes or not [42]. The WHO has used two parameters to define prediabetes: the IFG presented by the FPG of 110 to 125 $\mathrm{mg} / \mathrm{dL}$ and the IGT presented by the 2-hr plasma glucose of $140-200 \mathrm{mg} / \mathrm{dL}$ after ingestion of $75 \mathrm{~g}$ of oral glucose load or a combination of the two based on a 2-hr OGTT [4].

The ADA has the same cut-off value for IGT (2-hr plasma glucose of $140-200 \mathrm{mg} / \mathrm{dL}$ ) but has a lower cut-off value for IFG (FPG of 100-125 mg/dL) and has additional hemoglobin A1c based criteria $>5.7 \%$ to $6.4 \%$ for the diagnosis of prediabetes [5].

Prediabetes has been identified by mildly elevated glycated A1c. However, given the low sensitivity and /or 
specificity to detect low/intermediary levels of dysglycemia that characterize prediabetes; it has been suggested to use this test in conjunction with a FPG or OGTT to enhance the diagnostic accuracy. As such, IFG and IGT remain the current recommendations for the identification and diagnosis of prediabetes [47].

The Canadian Practice Guidelines has also the same cut off value for IGT ( $2 \mathrm{hr}$ plasma glucose of $140-200 \mathrm{mg} / \mathrm{dL}$ ), as for IFG it has the same cut off value as the WHO (FPG of 110 to $125 \mathrm{mg} / \mathrm{dL}$ ) and has as the ADA, A1c based criteria of a level of $5.7 \%$ to $6.4 \%$ for the diagnosis of prediabetes [3].

According to the IDF, levels of FBG between 100 to 125 $\mathrm{mg} / \mathrm{dL}$ or 2-hour glucose following ingestion of 75-g glucose load levels between 140-199 mg/dL defines prediabetes. Increased levels of A1c in the non-diabetic interval can also be used to diagnose people at risk of T2DM [38].

In this regard, the panel agreed that the fasting blood glucose is more practical and easier to be applied and less costly than any other tests. Therefore, the FBG should be measured after a standardized fasting time of 8 hours, The Jordanian expert panel also suggested levels of A1c levels to be followed.

Table 3. Jordanian Recommendation for Prediabetes Diagnostic Tests CutOffs.

\begin{tabular}{ll}
\hline FBG & $\geq 100-\leq 125 \mathrm{mg} / \mathrm{dl}$ \\
Alc & $\geq 5.7-\leq 6.4 \%$ (ADA guidelines) \\
2 hours OGTT $*$ & $\geq 140-\leq 199 \mathrm{mg} / \mathrm{dl}$ \\
\hline
\end{tabular}

*OGTT should be considered in certain cases.

\subsection{Management of Prediabetes}

Understanding prediabetes and managing it properly and timely, help in reducing the epidemic of T2DM [38]. The combination of physical activity and healthy weight management are two of the best management options to treat prediabetes according the AHA and the ADA. Lifestyle intervention in prediabetes should aim to reduce weight by $5 \%$ to $10 \%$ and maintain it for long periods of time. To achieve this objective, a program of regular moderate-intensity physical activity for 30-60 minutes daily is recommended at least 5 days/week along with a diet that includes caloric restriction, increased fiber intake, and (in some cases) carbohydrate intake limitations [6]. Many studies demonstrated the positive effects of lifestyle intervention during a period ranging from 2.8 to 6 years [13, 14, 48-51]. Even losing some weight for those who are overweight can have meaningful reductions in blood glucose.

By committing to and maintaining a healthy lifestyle (follow a healthy dietary pattern, lose body weight mainly from fats, increase physical activity, stop smoking and decrease stress), some people are able to reverse their prediabetes or avoid or postpone its progression to diabetes [48].

Medications such as biguanides, thiazolidinediones, $\alpha$ glucosidase inhibitors, GLP-1 receptor agonists may be prescribed to manage prediabetes [7]. Other interventions such as anti-obesity drugs and bariatric surgery may also be needed [7].

The results of the Diabetes Prevention Program (DPP) Research Group showed that both metformin and intensive lifestyle intervention significantly reduced the risk of developing T2DM, by $-31 \%$ and by $-58 \%$, respectively. It was also noted that lifestyle intervention is more effective in preventing diabetes as populations age and weight increases. After 10 years follow-up, the reduction in the risk of developing T2DM was $-18 \%$ and $-34 \%$, respectively [ 48,49$]$.

Similar results were seen in the Finnish Diabetes Prevention study with a reduction of $58 \%$ in the incidence of diabetes over 4 years after diet intervention and the Da Qing Diabetes Prevention study (longest follow-up of 20 years) where the combined lifestyle intervention groups had a 51\% lower incidence of diabetes in the first 6 years and a $43 \%$ lower incidence over the 20 -year period [50]. A metaanalysis of US studies on body weight change showed a $71 \%$ weight regain after 4.5 years [52].

The DPP 10-Year Cost-Effectiveness results showed that lifestyle is cost-effective and metformin is marginally costsaving versus placebo. Investment in lifestyle and metformin interventions for diabetes prevention in high-risk adults was considered as good value [49].

The expert panel recommendations are summarized in figure 1. Pharmacotherapy can be considered from day one in parallel with lifestyle management in certain cases.

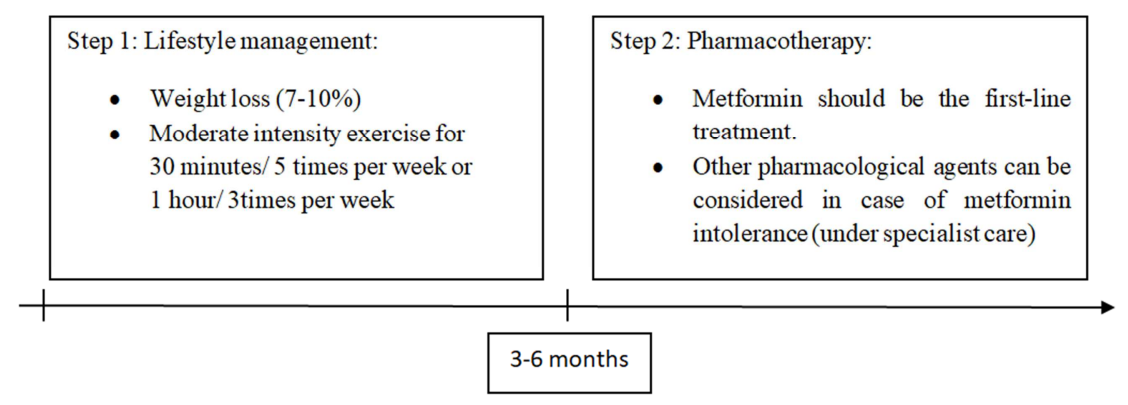

Figure 1. Jordanian Recommendation for Prediabetes Management.

Those above 50 years old should have a regular cardiac assessment before commencing on exercise.

Metabolic surgery (Bariatric surgery) is an option for morbidly obese patient with prediabetes.

\subsection{Metformin Dosage in Prediabetes}

In the DPP study, subjects were randomly assigned to $850 \mathrm{mg}$ 
metformin twice daily $(\mathrm{n}=1,073)$ or placebo $(\mathrm{n}=1,082)$ and followed up for 2.8 years. The results showed excellent adherence to metformin despite gastrointestinal side effects and a $31 \%$ decrease in the risk of developing diabetes. The optimal benefit was observed in patients with BMI $35 \mathrm{~kg} / \mathrm{m}^{2}$ - a $50 \%$ decrease in the risk of progressing to T2DM. A reduction of 1.7 $\mathrm{kg}$ was observed in the metformin group versus $0.3 \mathrm{~kg}$ weight gain in the placebo group. The weight reduction leading to improved insulin sensitivity and pancreatic function is viewed as a possible mechanism for reducing the risk of progressing to frank diabetes [16, 48, 49, 53].

Similarly, in the Canoe trial where metformin $(500 \mathrm{mg})$ twice daily was combined with rosiglitazone $(2 \mathrm{mg})$ in 103 patients, there was a beneficial effect in preventing the conversion of IGT subjects to type 2 diabetes [54].

The expert group concluded discussions on interventions to manage prediabetes as follows:

1) The therapy should be initiated with one tablet of metformin either $500 \mathrm{mg}$ metformin immediate release or $500-750 \mathrm{mg}$ extended release once daily with the evening meal.

2) A stepwise increment of the metformin dose (5-7 days intervals) may improve gastro-intestinal tolerability. The recommended dose is $2000 \mathrm{mg}$ standard release in divided doses with meals or $2000 \mathrm{mg}$ XR once daily with the evening meal.

\section{Conclusion}

A literature review of the existing data on prediabetes, professional opinions and experience discussion between 10 diabetes experts resulted in a consensus on screening, detection, diagnosis and management of prediabetes in Jordan. The panel agreed that due to lack of local studies, Jordanian physicians should rely on international guidelines for cut-off values, mainly the ADA for prediabetes diagnosis. Moreover, subgroups with the metabolic syndrome should be identified and managed accordingly.

According to the Jordanian expert panel, FBG and A1c are the preferred tests for the diagnosis of prediabetes in Jordan and the cut off points that should be adopted are the following:

1. FBG for prediabetes diagnosis: $100-125 \mathrm{mg} / \mathrm{dl}$ as per the IDF guidelines

2. A1c: $5.7-6.4 \%$ as per the ADA guidelines

The Jordanian expert panel recommended that All people $>45$ years old without risk factors should be screened for prediabetes.

The expert group concluded discussions on pharmacological treatment for prediabetes management with metformin as the drug of choice in prediabetes management after failure of lifestyle management.

The expert panel agreed that more resources should be invested to properly manage prediabetes in Jordan.

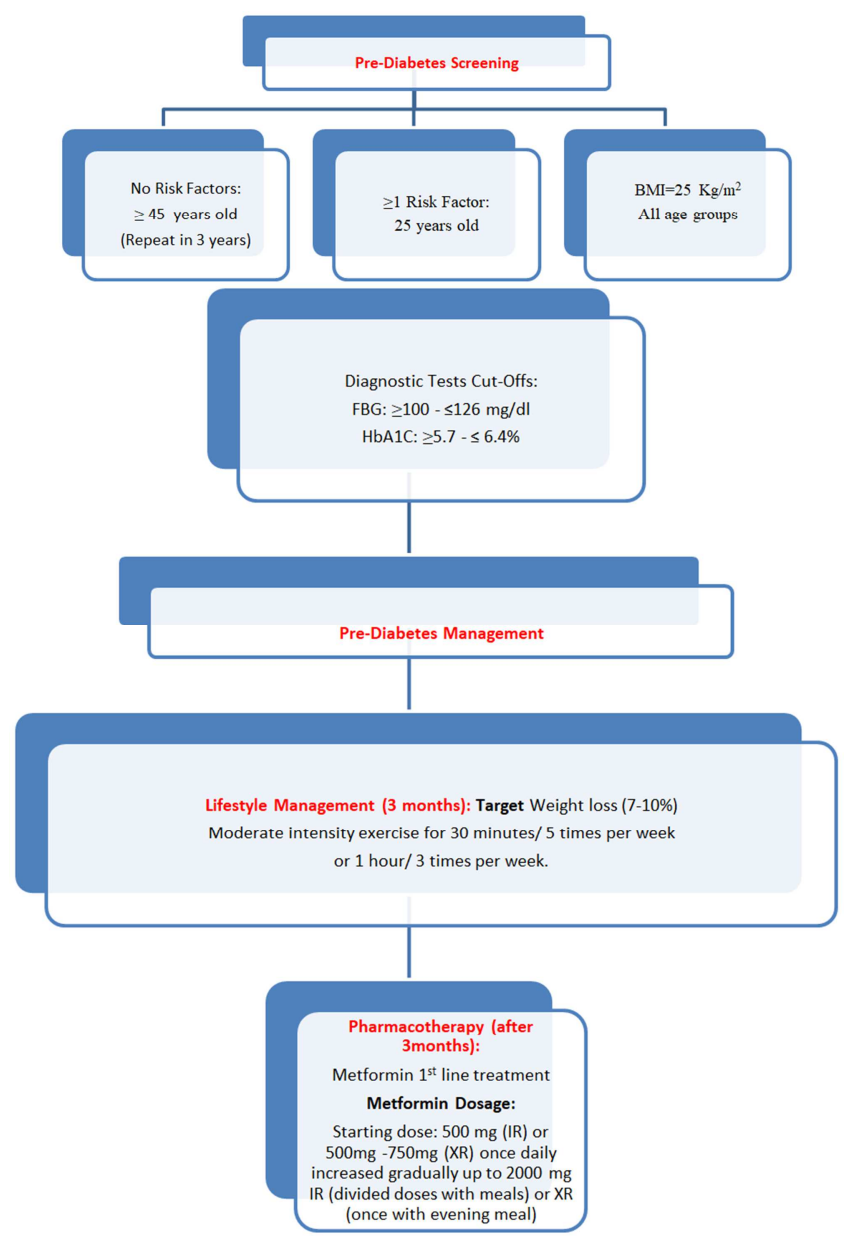

Figure 2. Jordanian Algorithm for Prediabetes Screening and Management. 


\section{Abbreviations}

AACE
ADA
AHA
BMI
BP
CKD
CVD
DECODE
DPP
FBG
FPG
GDM
GLP-1
HTN
IDF
IFG
IGT
MENA
NDDG
NHS
OGTT
PCOS
T2DM
USD
USPSTF
WHO

American Association of Clinical Endocrinologist

American Diabetes Association

American Heart Association

Body Mass Index

Blood Pressure

Chronic Kidney Disease

Cardiovascular Disease

Diabetes epidemiology: collaborative analysis of diagnostic criteria in Europe

Diabetes Prevention Program

Fasting Blood Glucose

Fasting Plasma Glucose

Gestational Diabetes Mellitus

Glucagon-Like Peptide-1

Hypertension

International Diabetes Federation

Impaired Fasting Glucose

Impaired Glucose Tolerance

Middle East and North Africa

National Diabetes Data Group

National Health Security

Oral Glucose Tolerance Test

Polycystic Ovary Syndrome

Type 2 Diabetes Mellitus

United States Dollars

United States Preventive Services Task Force

World Health Organization

\section{Disclosure}

Merck KGaA reviewed the manuscript for medical accuracy only before journal submission. The authors are fully responsible for the content of this manuscript, and the views and opinions described in the publication reflect solely those of the authors.

Both the research component and manuscript submission were financially supported by Merck KGaA Middle East-LTD.

\section{Author Disclosure}

The authors received fair market honorarium for their time spent attending the consensus meeting and developing the manuscript.

\section{Acknowledgements}

We would like to acknowledge the help of Dr. Mazen Matalka with the submission of the manuscript.

\section{References}

[1] Williams R. IDF Diabetes Atlas, $9^{\text {th }}$ Edition (2019): Global picture, $35 . \quad$ Viewed 29-10-2019, https://www.diabetesatlas.org/upload/resources/material/2020 0302_133351_IDFATLAS9e-final-web.pdf.

[2] World Health Organization. (2018). Obesity and overweight.
Viewed 29-10-2019, https://www.who.int/news-room/factsheets/detail/obesity-and-overweight.

[3] Punthakee Z, Goldenberg R, and Katz P. Diabetes Canada Clinical Practice Guidelines Expert Committee. Definition, classification and diagnosis of Diabetes, Prediabetes and Metabolic Syndrome. Can J Diabetes. 2018 Apr; 42 Suppl 1: S10-S15. doi: 10.1016/j.jcjd.2017.10.003.

[4] World Health Organization. (2006). Definition and Diagnosis of Diabetes Mellitus and Intermediate Hyperglycemia: Report of a WHO/IDF consultation; WHO: Geneva, Switzerland. Viewed 29-10-2019, http://www.who.int/diabetes/publications/Definition\%20and\% 20diagnosis\%20of\%20diabetes_new.pdf.

[5] American Diabetes Association. Classification and diagnosis of diabetes: Standards of Medical Care in Diabetes. Diabetes Care 2019; 42 (Suppl. 1): S13-S28. https://doi.org/10.2337/dc19-S002.

[6] Garber A, Handelsman Y, Einhorn D, et al. Diagnosis and Management of Prediabetes in the Continuum of Hyperglycemia - When do the Risks of Diabetes Begin? A Consensus Statement from the American College of Endocrinology and the American Association of Clinical Endocrinologists. Endocr Pract. 2008 Oct; 14 (7): 933-46. doi: 10.4158/EP.14.7.933.

[7] Bansal, N. Prediabetes diagnosis and treatment: A review. World J Diabetes. 2015; Mar 15; 6 (2): 296-303.

[8] Moss SE., Klein R, and Klein B E. The Validity of Estimating the Incidence of Diabetic Retinopathy from Prevalence. $A m J$ Epidemiol. 1990; Apr; 131 (4): 644-51. doi: 0.1093 /oxfordjournals.aje.a1 15548 . 
[9] Gabir, MM, Hanson RL, Dabelea D, Imperatore G, Roumain J, Bennett PH, and Knowleret WC. Plasma Glucose and Prediction of Microvascular Disease and Mortality. Diabetes Care. 2000 Aug; 23 (8): 1113-8. doi: 10.2337/diacare.23.8.1113.

[10] Nielson C. and Lange T. Blood Glucose and Heart Failure in Nondiabetic Patients. Diabetes Care. 2005 Mar; 28 (3): 60711. doi: 10.2337/diacare.28.3.607.

[11] Nielson C., Lange T. and Hadjokas N. Blood Glucose and Coronary Artery Disease in Nondiabetic Patients. Diabetes Care. 2006 May; 29 (5): 998-1001. doi: 10.2337/diacare.295998.

[12] Yip W C Y, Sequeira IR, Plank LD, and Poppitt SD. Prevalence of Prediabetes across Ethnicities: A review of impaired fasting glucose (IFG) and Impaired Glucose Tolerance (IGT) for classification of dysglycaemia. Nutrients. 2017 Nov 22; 9 (11): 1273. doi: 10.3390/nu9111273.

[13] Knowler WC, Barrett-Connor E, Fowler SE,. Diabetes Prevention Program Research Group. Reduction in the incidence of type 2 diabetes with lifestyle intervention or Metformin. N Engl J Med. 2002 Feb 7; 346 (6): 393-403. doi: 10.1056/NEJMoa012512.

[14] Gillies CL, Abrams KR, Lambert PC, et al. Pharmacological and lifestyle interventions to prevent or delay type 2 diabetes in people with impaired glucose tolerance: systematic review and meta-analysis. BMJ. 2007 Feb 10; 334 (7588): 299. doi: 10.1136/bmj.39063.689375.55. Epub 2007 Jan 19.

[15] Chiasson JL, Josse RG, Gomis R, Hanefeld M, Karasik A, and Laakso A. Acarbose treatment and the risk of cardiovascular disease and hypertension in patients with impaired glucose tolerance: the STOP-NIDDM trial. JAMA. 2003 Jul 23; 290 (4): 486-94. doi: 10.1001/jama.290.4.486.

[16] Ratner R, Goldberg R, Haffneret S, et al. Impact of intensive lifestyle and metformin therapy on cardiovascular disease risk factors in the diabetes prevention program. Diabetes Care. 2005 Apr; 28 (4): 888-94. doi: 10.2337/diacare.28.4.888.

[17] Dagenais GR. Dagenais GR, Gerstein HC, et al. Effects of Ramipril and Rosiglitazone on cardiovascular and renal outcomes in people with impaired glucose tolerance or impaired fasting glucose: results of the diabetes reduction assessment with Ramipril and Rosiglitazone medication (DREAM) trial. Diabetes Care. 2008 May; 31 (5): 1007-14. doi: $10.2337 / \mathrm{dc} 07-1868$.

[18] Boutayeb A, Lamlili ME, Boutayeb W, Maamri A, Ziyyat A, and Ramdani N. The rise of diabetes prevalence in the Arab region. 2012; Open Journal of Epidemiology 2 (02): 55-60

[19] Mokdad AH, Tuffaha M, Hanlon M, et al. Cost of Diabetes in the Kingdom of Saudi Arabia, 2014. J Diabetes Metab 2015, 6: 8 http://dx.doi.org/10.4172/2155-6156.1000575

[20] Alarouj M, Bennakhi A, Alnesef Y, Sharifi M, and Elkum N. Diabetes and associated cardiovascular risk factors in the State of Kuwait: The first national survey. Int J Clin Pract. 2013 Jan; 67 (1): 89-96. doi: 10.1111/ijcp. 12064.

[21] Al Zurba Fl, and Al Garf A. Prevalence of diabetes mellitus among Bahrainis attending primary health care centres. EMHJ. 1996; 2 (2): 274-282.

[22] Malik M, Bakir A, Saab BA, and King, H. Glucose intolerance and associated factors in the multi-ethnic population of the United Arab Emirates: results of a national survey. Diabetes Res Clin Pract. 2005 Aug; 69 (2): 188-95. doi: 10.1016/j.diabres.2004.12.005.

[23] Mansour AA. Al-Maliky AA, Kasem B, Jabar A, and Mosbeh KA. Prevalence of diagnosed and undiagnosed diabetes mellitus in adults aged 19 years and older in Basrah, Iraq. Diabetes Metab Syndr Obes. 2014 May 2; 7: 139-44. doi: 10.2147/DMSO.S59652. eCollection 2014.

[24] Al-Lawati JA, Panduranga P, Al-Shaikh HA, et al. Epidemiology of Diabetes Mellitus in Oman. Sultan Qaboos Univ Med J. 2015 May; 15 (2): e226-33. Epub 2015 May 28.

[25] Bener A, Zirie M, Janahi IM, Al-Hamaq AO, Musallam M, and Wareham NJ. Prevalence of diagnosed and undiagnosed diabetes mellitus and its risk factors in a population-based study of Qatar. Diabetes Res Clin Pract. 2009 Apr; 84 (1): 99106. doi: 10.1016/j.diabres.2009.02.003.

[26] Gunaid, AA and Assabri AM. Prevalence of type 2 diabetes and other cardiovascular risk factors in a semirural area in Yemen. East Mediterr Health J. Jan-Feb 2008; 14 (1): 42-56.

[27] Abdul Rahim HF, Husseini A, Giacaman R, Jervell J, and Bjertness E. Diabetes mellitus in an urban Palestinian population: prevalence and associated factors. EMHJ. 2001; 7 (1-2): 67-78.

[28] Albache, N. Al Ali R, Rastam S, Fouad FM, Mzayek F, and Maziak W. Epidemiology of Type 2 diabetes mellitus in Aleppo, Syria. J Diabetes. 2010 Jun; 2 (2): 85-91. doi: 10.1111/j.1753-0407.2009.00063.x. Epub 2009 Nov 2.

[29] Hirbli KI, Jambeine MA, Slim HB, Barakat WM, and Habis RJ, Francis ZM. Prevalence of diabetes in greater Beirut. Diabetes Care. 2005 May; 28 (5): 1262. doi: 10.2337/diacare.28.5.1262.

[30] Ben Rodhane H, Ben Ali S, Aissi W, et al. Prevalence of diabetes in Northern African countries: the case of Tunisia. BMC Public Health. 2014 Jan 28; 14: 86. doi: 10.1186/14712458-14-86.

[31] Kadiki OA and Roaeid R. Prevalence of diabetes mellitus and impaired glucose tolerance in Benghazi Libya. Diabetes Metab. 2001 Dec; 27 (6): 647-54.

[32] Rguibi $M$ and Belahsen R. Prevalence and associated risk factors of undiagnosed diabetes among adult Moroccan Sahraoui women. Public Health Nutr. 2006 Sep; 9 (6): 722-7. doi: $10.1079 / \mathrm{phn} 2005866$.

[33] Ajlouni K, Jaddou H, and Batieha A. Diabetes and impaired glucose tolerance in Jordan: prevalence and associated risk factors. J Intern Med. 1998 Oct; 244 (4): 317-23. doi: 10.1046/j.1365-2796.1998.00369.x.

[34] The Ministry of Health of Jordan. The National Strategy And Plan Of Action Against Diabetes, Hypertension, Dyslipidemia And Obesity in Jordan. Viewed 290ct., 2019, https://www.moh.gov.jo/EchoBusV3.0/SystemAssets/PDFs/P DFs $\% 20 A R /$ Strategies_AR/\%D8\%A7\%D9\%84\%D8\%A7\%D 8\%B3\%D8\%AA\%D8\%B1\%D8\%A7\%D8\%AA\%D9\%8A\%D 8\%AC\%D9\%8A\%D8\%A9\%20\%D8\%A7\%D9\%84\%D9\%88 \%D8\%B7\%D9\%86\%D9\%8A\%D8\%A9\%20\%D9\%84\%D9\% 84\%D9\%88\%D9\%82\%D8\%A7\%D9\%8A\%D8\%A9\%20\%D9 \%85\%D9\%86\%20\%D8\%A7\%D9\%84\%D8\%A7\%D9\%85\%D 8\%B1\%D8\%A7\%D8\%B6\%20\%D8\%BA\%D9\%8A\%D8\%B1 \%20\%D8\%A7\%D9\%84\%D8\%B3\%D8\%A7\%D8\%B1\%D9\% 8A\%D8\%A9.pdf. 
[35] Tabák AG, Herder C, Rathmann W, Brunne EJr, and Kivimäki M. Prediabetes: a high-risk state for diabetes development. Lancet. 2012 Jun 16; 379 (9833): 2279-90. doi: 10.1016/S0140-6736(12)60283-9.

[36] International Diabetes Federation (2017). IDF Diabetes Atlas 8th Edition. Viewed 29-10-2019, https://www.idf.org/elibrary/epidemiology-research/diabetes-atlas.html.

[37] Al-Rifai RH and Aziz F. Prevalence of type 2 diabetes, prediabetes, and gestational diabetes mellitus in women of childbearing age in Middle East and North Africa, 2000-2017: protocol for two systematic reviews and meta-analyses. Syst Rev. 2018 Jul 18; 7 (1): 96. doi: 10.1186/s13643-018-0763-0.

[38] World Health Organization. (2016). Jordan. Viewed 29102019 , profiles/jor_en.pdf

[39] The DECODE Study Group. Age- and Sex-Specific Prevalences of Diabetes and Impaired Glucose Regulation in 13 European Cohorts. Diabetes Care. 2003 Jan; 26 (1): 61-9. doi: 10.2337/diacare.26.1.61.

[40] Al-Shudifat AE, Al-Shdaifat A, Al-Abdouh AA. et al. Diabetes Risk Score in a Young Student Population in Jordan: A CrossSectional Study. J Diabetes Res. 2017; 2017: 8290710. doi: 10.1155/2017/8290710.

[41] Dajani R, Khader YS, Fatahallah R, El-Khateeb M, Shiyab A, and Hakooz N. Diabetes mellitus in genetically isolated populations in Jordan: prevalence, awareness, glycemic control, and associated factors. J Diabetes Complications. May-Jun 2012; $26 \quad$ (3): $175-80 . \quad$ doi: 10.1016/j.jdiacomp.2012.03.009.

[42] Dorcely B, Katz K, Jagannathan R, et al. Novel Biomarkers for prediabetes, diabetes, and associated complications. Diabetes, Metabolic Syndrome and Obesity: Targets and Therapy. 2017; 10: 345-361.

[43] The United States Preventive Services Task Force. (2015). Abnormal Blood Glucose and Type 2 Diabetes Mellitus: Screening. $\quad$ Viewed 29 Oct., 2019, https://www.uspreventiveservicestaskforce.org/Page/Documen $\mathrm{t} /$ UpdateSummaryFinal/screening-for-abnormal-bloodglucose-and-type-2-diabetes.

[44] American Diabetes Association (2018). Standards of Medical Care in Diabetes 2018. Diabetes Care, 41 (1). Viewed 29 Oct., 2019, http://diabetesed.net/wp-content/uploads/2017/12/2018ADA-Standards-of-Care.pdf.
[45] International Diabetes Federation. (2003). Test2Prevent: Know Your Risk. Viewed 29Oct., 2019, https://www.idf.org/type-2-diabetes-risk-assessment/.

[46] Buysschaert M. Medina JL, Buysschaert B, and Bergmanet M Definitions (and Current Controversies) of Diabetes and Prediabetes. Curr Diabetes Rev. 2016; 12 (1): 8-13. doi: $10.2174 / 1573399811666150122150233$

[47] Guo F, Moellering, DR, and Garvey WT. Use of HbA1c for diagnoses of diabetes and prediabetes: comparison with diagnoses based on fasting and 2-hr glucose values and effects of gender, race, and age. Metab Syndr Relat Disord. 2014; 12 (5): 258-268.

[48] Knowler WC, Barrett-Connor E, Fowler SE, et al. Diabetes Prevention Program Research Group. Reduction in the Incidence of Type 2 Diabetes with Lifestyle Intervention or Metformin. N Engl J Med. 2002 Feb 7; 346 (6): 393-403. doi: 10.1056/NEJMoa012512.

[49] The Diabetes Prevention Program Research Group. The 10Year Cost-Effectiveness of Lifestyle Intervention or Metformin for Diabetes Prevention. Diabetes Care. 2012 Apr; 35 (4): 723-30. doi: 10.2337/dc11-1468.

[50] Lindström J, Louheranta A, Mannelin M, el al. The Finnish Diabetes Prevention Study (DPS) Lifestyle intervention and 3year results on diet and physical activity. Diabetes Care. 2003 Dec; 26 (12): 3230-6. doi: 10.2337/diacare.26.12.3230.

[51] Li G, Zhang P, Wang P, et al. The long-term effect of lifestyle Interventions to prevent diabetes in the China Da Qing Diabetes Prevention Study: a 20-year follow-up study. Lancet. 2008 May 24; 371 (9626): 1783-9. doi: 10.1016/S01406736(08)60766-7.

[52] Andersen J, Konz EC, Frederich RC, and Wood CL. Longterm weight-loss maintenance: a meta-analysis of US studies. Am J Clin Nutr. 2001 Nov; 74 (5): 579-84. doi: 10.1093/ajcn/74.5.579.

[53] Aroda VR, Knowler WC, Crandall JP, et al. Metformin for diabetes prevention: insights gained from the Diabetes Prevention Program/Diabetes Prevention Program Outcomes Study. Diabetologia. 2017 Sep; 60 (9): 1601-1611. doi: 10.1007/s00125-017-4361-9.

[54] Zinman B, Harris SB, Neuman J, et al. Low-dose combination therapy with Rosiglitazone and Metformin to prevent type 2 diabetes mellitus (CANOE trial): a double-blind randomised controlled study. Lancet. 2010 Jul 10; 376 (9735): 103-11. Doi 10.1016/S0140-6736(10)60746-5. Epub 2010 Jun 3. 